\title{
Human immunodeficiency virus type-1 can be detected in monocytes by polymerase chain reaction
}

\author{
EUGENIA QUIRÓS, F. GARCIA*, MARIA DEL CARMEN MAROTO, MARIA DEL CARMEN BERNAL, \\ TERESA CABEZAS and G. PIEDROLA
}

Department of Microbiology, Faculty of Medicine and School of Infirmary, University of Granada, 18012 Granada, Spain

\begin{abstract}
Summary. Lymphocytes and monocytes from 25 patients infected with human immunodeficiency virus type-1 (HIV-1) - 13 asymptomatic, seven with the AIDS-related complex (ARC) and five with the acquired immunodeficiency syndrome (AIDS) - were lysed and subjected to PCR with three primer pairs: SK38/SK39 (gag), SK68/SK69 (env) and SK29/SK30 (LTR). Amplified DNA was solution-hybridised with ${ }^{32} \mathrm{P}$-labelled probes (SK19, SK 70 and SK 31, respectively) and detected by PAGE-autoradiography. HIV-1 DNA was detected as follows. Asymptomatic patients: monocytes-gag 61.5\%, env $100 \%$, LTR $0 \%$; lymphocytes-gag $100 \%$, env $92.3 \%$, LTR $53.84 \%$. ARC patients: monocytes-gag $71 \cdot 4 \%$, env $57 \cdot 1 \%$, LTR $0 \%$; lymphocytes-gag $100 \%$, env $71 \cdot 4 \%$, LTR $71 \cdot 4 \%$. AIDS patients: monocytes-gag $80.0 \%$, env $100 \%$, LTR $0 \%$; lymphocytes-gag $100 \%$, env $60 \%$, $L T R 60 \%$. The presence of HIV-1 DNA was confirmed in the monocyte fraction. In this cell subset, the env gene-directed primers were the most effective for amplification, whereas the $L T R$ gene-directed primers failed to amplify HIV-1 DNA. The different pattern of amplification found in monocytes may suggest that these cells could be infected by a genetic variant of the virus.
\end{abstract}

\section{Introduction}

Human immunodeficiency virus type-1 (HIV-1) has been detected in peripheral blood mononuclear cells (PBMC) ${ }^{11}$ several authors have studied its presence in different PBMC subsets ${ }^{2-4}$ but no firm conclusions have yet been reached. HIV-1 can infect the macrophage-monocyte fraction because CD4 receptors are expressed in these cells ${ }^{5}$ and the virus has also been cultured from monocytes of infected patients. ${ }^{6}$ However, HIV-1 has never been isolated from $\mathrm{CD}^{+}$lymphocytes, perhaps because this subset does not express CD4 receptors.

HIV-1 can produce a latent infection of CD4 cells and its DNA is frequently integrated into the genome of these cells; conversely, HIV-1 RNA is rarely detected in CD4 lymphocytes which again indicates latent infection. Although HIV-1 can produce infection of the monocyte-macrophage fraction of PBMC, HIV-1 DNA has not been shown, so far, to be present in these cell subsets. ${ }^{7}$ The possibility that HIV1 may infect a different cell subset needs to be

Received 11 Aug. 1994; revised version accepted 5 Dec. 1994.

* Correspondence should be sent to Dr F. García. examined. The finding of a different pattern of detection of genes from HIV-1 in peripheral blood subsets other than CD4 lymphocytes, in an individual patient, may indicate that naturally- or treatmentselected variants of the virus are present. ${ }^{8}$ If this is so, new treatment strategies need to be established.

Therefore, the detection of HIV-1 DNA in the macrophage-monocyte fraction may be a key to the solution of some problems related to HIV-1 infection. The aim of this investigation was to study the presence of HIV-1 in monocytes by means of the polymerase chain reaction (PCR).

\section{Patients and methods}

Blood was obtained from 25 HIV seropositive patients: 13 asymptomatic carriers, seven with the AIDS-related complex (ARC) and five with the acquired immunodeficiency syndrome (AIDS).

\section{Isolation of cell subsets}

The mononuclear cell fraction was separated from the red blood cell fraction by Ficoll-Hypaque density 
Table I. CD4 and CD8 count and gag, env and LTR amplification in lymphocytes and monocytes from asymptomatic carriers of HIV

\begin{tabular}{|c|c|c|c|c|c|c|c|c|}
\hline \multirow{2}{*}{ Case no. } & \multirow{2}{*}{$\begin{array}{l}\text { CD4/CD8 } \\
\text { count }\end{array}$} & \multicolumn{3}{|c|}{ Lymphocytes } & \multicolumn{3}{|c|}{ Monocytes } & \multirow{2}{*}{$\mathrm{AZT} / \mathrm{IFN}$} \\
\hline & & $g a g$ & $e n v$ & $L T R$ & gag & env & $L T R$ & \\
\hline 1 & $1123 / 1556$ & + & - & - & - & + & - & No \\
\hline 2 & $839 / 952$ & + & + & + & + & + & - & $-1+$ \\
\hline 3 & $765 / 1097$ & + & + & + & + & + & - & $-1+$ \\
\hline 4 & $874 / 1014$ & + & + & - & - & + & - & No \\
\hline 5 & $579 / 984$ & + & + & + & + & + & - & No \\
\hline 6 & $602 / 859$ & + & + & + & - & + & - & No \\
\hline 7 & $369 / 876$ & + & + & - & - & + & - & $-/+$ \\
\hline 8 & $623 / 930$ & + & + & + & + & + & - & No \\
\hline 9 & $650 / 858$ & + & + & - & - & + & - & $+1-$ \\
\hline 10 & $766 / 1107$ & + & + & - & + & + & - & No \\
\hline 11 & $697 / 2010$ & + & + & + & + & + & - & No \\
\hline 12 & $512 / 1870$ & + & + & - & + & + & - & No \\
\hline 13 & $402 / 1460$ & + & + & + & + & + & - & $+1-$ \\
\hline Total (\%) & & 100 & $92 \cdot 3$ & 53.84 & $61 \cdot 5$ & 100 & 0 & \\
\hline
\end{tabular}

CD4/CD8, T cell count; AZT/IFN, treatment with azidothymidine/ $\alpha$-interferon

gradient centrifugation. T lymphocytes were separated from other mononuclear cells by the rosette test and a second Ficoll-Hypaque density gradient centrifugation. To isolate the monocyte fraction, mononuclear cells were cultured for $24 \mathrm{~h}$ to eliminate dendritic and $\mathrm{B}$ cells, and then allowed to adhere for $1 \mathrm{~h}$ on to plastic dishes and washed twice with RPMI 1640 medium with fetal calf serum $10 \%$. The adherent cells were incubated for $20 \mathrm{~min}$ at $37^{\circ} \mathrm{C}$ in $3 \mathrm{~mm}$ EDTA. Monocytes were detached by vigorous pipetting and analysed by FACscan flow cytometry to detect contamination with $\mathrm{T}$ lymphocytes; only monocyte fractions without contaminating $T$ cells were processed further. After isolation, cells were washed twice in PBS and incubated for $1 \mathrm{~h}$ at $60^{\circ} \mathrm{C}$ in a lysis buffer containing $50 \mathrm{mM} \mathrm{KCl}, 10 \mathrm{mM}$ Tris- $\mathrm{HCl}, 2.5 \mathrm{~mm}$ $\mathrm{MgCl}_{2}$, Tween $20,0.5 \%$, Nonidet P-40 0.5\% and 0.06 proteinase $\mathrm{K} \mathrm{g} / \mathrm{L}$. After disruption, proteinase $\mathrm{K}$ was inactivated by heating at $95^{\circ} \mathrm{C}$ for $10 \mathrm{~min}$.

\section{Nucleic acid amplification}

HIV-DNA was amplified with three sets of primers from different regions of the HIV-1 genome: SK 38/39 (1551-1578 and 1638-1665), which amplifies a conserved gag region of $114 \mathrm{bp}$; SK68/69 (7801-7829 and 7922-7942) which amplifies a conserved 141-bp region of the env gene; and SK29/30 (501-518 and 589-604) which amplifies a 104-bp fragment from the $L T R$ gene. ${ }^{9}$ The reaction was performed in $10 \times$ Taq buffer $(500 \mathrm{~mm} \mathrm{KCl}, 100 \mathrm{~mm}$ Tris- $\mathrm{HCl}, \mathrm{pH} 8 \cdot 3,25 \mathrm{~mm}$ $\mathrm{MgCl}_{2}$, gelatin $0.1 \%$ ); the rest of the components were: primers, 50 pmol each; dNTPs, $50 \mu \mathrm{M}$ each; Taq polymerase $2.5 \mathrm{U} ; 25 \mu \mathrm{l}$ of cell lysate containing $1 \times 10^{6} \mathrm{~T}$ cells or monocytes, equivalent to $1 \mu \mathrm{g}$ of genomic DNA. The reaction, consisting of 30 cycles $\left(94^{\circ} \mathrm{C}\right.$ for $1 \mathrm{~min}, 55^{\circ} \mathrm{C}$ for $2 \mathrm{~min}$ and $72^{\circ} \mathrm{C}$ for $3 \mathrm{~min}$ ) was carried out in a thermal cycler (Perkin-Elmer). Solution hybridisation with ${ }^{32} \mathrm{P}$-labelled probes was performed (SK19, SK70 and SK31 for SK38/39, SK68/69 and SK29/30 products, respectively); the hybridisation product was detected by polyacrylamide gel electrophoresis (PAGE) and autoradiography.

To test the suitability of the lysates, samples were also amplified with a set of HLA primers (GH26/27), which flank a conserved region of HLA-DQ $(\alpha)$ locus and hybridised with a ${ }^{32} \mathrm{P}$-labelled probe (GH64). ${ }^{10} \mathrm{~A}$ set of positive $\left(\mathrm{ACH}_{2}\right.$ cell line containing one copy of HIV provirus/cell) and negative (uninfected cells and a blank control - reaction tube without cells) controls were used.

\section{Results}

Detection of gag, env and LTR genes in cell subsets from asymptomatic patients

HIV-1 DNA was detected in lymphocytes from all 13 patients with primers directed against the gag gene, $12(92.3 \%)$ patients when $e n v$-directed primers were used and seven $(53.8 \%)$ patients with $L T R$-directed primers. When cells from the monocyte fraction were tested, amplified fragments were detected in eight $(61.5 \%)$ patients with gag-directed primers and 13 $(100 \%)$ patients with primers directed against the env gene; primers from the $L T R$ gene failed to amplify any DNA fragments. These results are shown in table I.

\section{Detection of gag, env and LTR genes in cell subsets} from $A R C$ patients

HIV-1 DNA was detected in lymphocytes from all seven patients with primers directed against the gag gene, five $(71.4 \%)$ patients when $e n v$-directed primers were used and five $(71.4 \%)$ patients with $L T R$-directed primers. When cells from the monocyte fraction were tested, amplified fragments were detected in five $(71.4 \%)$ patients with gag-directed primers and four $(57 \cdot 1 \%)$ patients with primers directed against the $e n v$ gene; primers from the $L T R$ gene failed to produce amplification products. These results are shown in table II. 
Table II. CD4 and CD8 count and gag, env and LTR amplification in lymphocytes and monocytes from ARC patients

\begin{tabular}{|c|c|c|c|c|c|c|c|c|}
\hline \multirow{2}{*}{ Case no. } & \multirow{2}{*}{$\begin{array}{l}\mathrm{CD} 4 / \mathrm{CD} 8 \\
\text { count }\end{array}$} & \multicolumn{3}{|c|}{ Lymphocytes } & \multicolumn{3}{|c|}{ Monocytes } & \multirow{2}{*}{$\mathrm{AZT} / \mathrm{IFN}$} \\
\hline & & $g a g$ & $e n v$ & $L T R$ & $g a g$ & env & $L T R$ & \\
\hline 1 & $302 / 1123$ & + & + & + & + & - & - & $+1+$ \\
\hline 2 & $240 / 864$ & + & + & - & + & + & - & $+1-$ \\
\hline 3 & $415 / 1263$ & + & - & - & + & + & - & $+1+$ \\
\hline 4 & $237 / 2223$ & + & + & + & - & - & - & $+1-$ \\
\hline 5 & $309 / 1875$ & + & + & + & + & - & - & $+1-$ \\
\hline 6 & $464 / 1319$ & + & - & + & + & + & - & $+1+$ \\
\hline 7 & $345 / 2196$ & + & + & + & + & + & - & $+1-$ \\
\hline Total (\%) & & 100 & $71 \cdot 4$ & $71 \cdot 4$ & $71 \cdot 4$ & $57 \cdot 1$ & 0 & \\
\hline
\end{tabular}

CD4/CD8, T cell count AZT/IFN, treatment with azidothymidine/ $\alpha$-interferon.

Table III. CD4 and CD8 count and gag, env and $L T R$ amplification in lymphocytes and monocytes from AIDS patients

\begin{tabular}{|c|c|c|c|c|c|c|c|c|}
\hline \multirow{2}{*}{ Case no. } & \multirow{2}{*}{$\begin{array}{l}\mathrm{CD} 4 / \mathrm{CD} 8 \\
\text { count }\end{array}$} & \multicolumn{3}{|c|}{ Lymphocytes } & \multicolumn{3}{|c|}{ Monocytes } & \multirow{2}{*}{$\mathrm{AZT} / \mathrm{IFN}$} \\
\hline & & $g a g$ & $e n v$ & $L T R$ & $g a g$ & env & $L T R$ & \\
\hline 1 & $198 / 899$ & + & - & - & - & + & - & $+1+$ \\
\hline 2 & $181 / 462$ & + & - & - & + & + & - & $+1+$ \\
\hline 3 & $92 / 827$ & + & + & + & + & + & - & $+1-$ \\
\hline 4 & $200 / 758$ & + & + & + & + & + & - & $+1-$ \\
\hline 5 & $214 / 867$ & + & + & + & + & + & - & $+1-$ \\
\hline Total $(\%)$ & & 100 & 60 & 60 & 80 & 100 & 0 & \\
\hline
\end{tabular}

CD4/CD8, T cell count; AZT/IFN, treatment with azidothymidine/ $\alpha$-interferon.

\section{Detection of gag, env and LTR genes in cell subsets} from AIDS patients

HIV-1 DNA was detected in lymphocytes from all five patients with primers directed against the gag gene, from three $(60 \%)$ patients when $e n v$-directed primers were used and three $(60 \%)$ patients with $L T R$-directed primers. When cells from the monocyte fraction were tested, amplification products were detected in four $(80 \%)$ patients with gag-directed primers and five $(100 \%)$ patients with primers directed against the env gene; primers from the $L T R$ gene failed to amplify any DNA fragments. These results are shown in table III.

The three primer pairs could detect as little as one copy of HIV-1 proviral DNA, as assessed by serial dilutions of $\mathrm{ACH}_{2}$ positive control cells.

\section{Discussion}

HIV-1 has been reported in many different localisations, ${ }^{11-16}$ but the main reservoirs are $\mathrm{PBMC}^{17}$ and lymphatic tissue. ${ }^{18} \mathrm{HIV}-1$ can produce a latent infection of CD4 lymphocytes but the virus is not present in CD8 cells $;{ }^{19}$ whether the virus is present or not in the monocyte fraction is not clear. ${ }^{2-4,7}$ PCR technology is a useful tool to study the presence of HIV-1 DNA in organs and tissues from infected patients. In this investigation, the presence of HIV-1 DNA in lymphocytes and monocytes from $25 \mathrm{HIV}$ seropositive patients was studied. Primers from the gag, env and $L T R$ genes were used to confirm HIV-1 infection and to determine the pattern of amplification in both cell subsets.

When PCR assays are used to confirm the presence of HIV-1 DNA in PBMC, positive results with at least two primer sets are necessary, because genomic variability is frequent. ${ }^{17,20-22}$ Following standard algorithms for HIV-1 PCR testing, ${ }^{22}$ positive results were obtained with lymphocytes from $12(92 \cdot 3 \%)$ asymptomatic carriers, five $(71.4 \%)$ ARC patients and three $(60 \%)$ AIDS patients. In the monocyte fraction, following the same algorithms, samples from eight $(61.5 \%)$ asymptomatic carriers, four $(57 \cdot 1 \%)$ ARC patients and four $(80.0 \%)$ AIDS patients were positive. Therefore, it can be stated that HIV-1 DNA can be detected in monocytes from patients at all stages of HIV-1 infection. These results are similar to those reported by McElrath et al. ${ }^{\mathbf{4} 23}$ who proposed that HIV-1 can produce a latent infection in monocytes in infected patients. However, others have reported a rather transient infection with HIV-1 in monocytes ${ }^{2}$ and a lower percentage of infection in this cell subset, ${ }^{3}$ or even the absence of infection. ${ }^{7}$ Although these authors show discordant results, some aspects of their reports need to be discussed. Firstly, for monocyte isolation we used a method that assures the absence of contaminating $\mathrm{T}$ lymphocytes, so the results for the monocyte fraction are representative. Secondly, those who propose that HIV-1 is not frequently present in monocytes used only primers from the gag gene 
(SK38/SK39) for amplification, because this is the most sensitive primer set to study HIV-1 in PBMC. In the present study, the most sensitive primer set for studying the presence of HIV-1 in monocytes was the env gene-directed set (SK68/SK69). Thus, if this primer set is not used, a low percentage of detection may result. When the SK68/SK69 primer set is used, the rate of detection of HIV-1 DNA in monocytes from infected patient rises. To determine whether the infection is replicative or latent, HIV-1 RNA should also be detected.

The env gene-directed primers were the most sensitive for HIV-1 DNA amplification in monocytes. Usually, when HIV-1 DNA is assayed for PCR in PBMC, gag gene-directed primers are the most sensitive, followed by env gene primer pairs and, finally, the $L T R$ gene-directed primer pairs which are the least sensitive. ${ }^{22}$ In this study, when these three primer pairs were used for PCR testing in lymphocytes, the same pattern was observed (asymptomatic carriers-gag, $100 \%$, env, $92 \cdot 3 \%, L T R, 53 \cdot 84 \%$; ARC patientsgag, $100 \%$, env, $71.4 \%, L T R, 71 \cdot 4 \%$; AIDS patients -gag, $100 \%$, env, $60 \%, L T R, 60 \%$ ); however, when they were used for PCR testing of the monocyte fraction, a different pattern of amplification was

\section{References}

1. He Y, Coutlee F, Saint-Antoine P, Olivier C, Voyer H, KessousElbaz A. Detection of polymerase chain reaction-amplified human immunodeficiency virus type-1 proviral DNA with a digoxigenin-labeled RNA probe and an enzyme-linked immunoassay. J Clin Microbiol 1993; 31: 1040-1047.

2. Hufert FT, von Laer D, Fenner TE, Schwander S, Kern P, Schmitz H. Progression of HIV-1 infection. Monitoring of HIV-1 DNA in peripheral blood mononuclear cells by PCR. Arch Virol 1991; 120: 233-240.

3. Spear GT, Ou C-Y, Kessler HA, Moore JL, Schochetman G, Landay AL. Analysis of lymphocytes, monocytes, and neutrophils from human immunodeficiency (HIV)-infected persons for HIV DNA. J Infect Dis $1990 ; 162$ : 1239-1244.

4. McElrath MJ, Steinman RM, Cohn ZA. Latent HIV-1 infection in enriched populations of blood monocytes and $\mathrm{T}$ cells from seropositive patients. J Clin Invest 1991; 87 : 27-30.

5. Clapham PR, Weber JN, Whitby D et al. Soluble CD4 blocks the infectivity of diverse strains of HIV and SIV for T cells and monocytes but not for brain and muscle cells. Nature 1989; 337: 368-370.

6. Landay A, Kessler HA, Benson CA et al. Isolation of HIV-1 from monocytes of individuals negative by conventional culture. J Infect Dis 1990; 161: 706-710.

7. Schnittman SM, Psallidopoulos MC, Lane HC et al. The reservoir for HIV-1 in human peripheral blood is a $\mathrm{T}$ cell that maintains expression of CD4. Science 1989; 245: 305-308.

8. Cordonnier A, Montagnier L, Emerman M. Single amino-acid changes in HIV envelope affect viral tropism and receptor binding. Nature 1989; 340: 571-574

9. Ou C-Y, Kwok S, Mitchell SW et al. DNA amplification for direct detection of HIV-1 in DNA of peripheral blood mononuclear cells. Science 1988; 239 : 295-297.

10. Scharf SJ, Horn GT, Ehrlich HA. Direct cloning and sequence analysis of enzymatically amplified genomic sequences. Science 1986; 233: 1076-1078.

11. Cao YZ, Dieterich D, Thomas PA, Huang YX, Mirabile M, Ho DD. Identification and quantitation of HIV-1 in the live of patients with AIDS. AIDS 1992; 6: 65-70.

12. Goswami KK, Miller RF, Harrison MJ, Hamel DJ, Daniels observed. In the monocyte fraction, env gene-directed primers were the most sensitive primer set (asymptomatic carriers, $100 \%$; ARC patients, $57.1 \%$; AIDS patients, $100 \%$ ), followed by gag gene primer pairs (asymptomatic carriers, $61.5 \%$; ARC patients, $71.4 \%$; AIDS patients, $80 \%$ ), and, surprisingly, no amplification was observed when $L T R$ gene-directed primer pairs were used. This pattern of amplification, which is different from the usual PBMC pattern and from the lymphocyte pattern, might suggest that a variant of HIV-1 infects the monocyte fraction. The most highly conserved gene in the genome of HIV-1 is the gag gene. The finding of patients whose monocytes harbour a virus where the most effective amplification is achieved with env-directed primers but not with gagdirected primers adds support to our observation, as does the fact that $L T R$ gene-directed primers always failed to amplify HIV-1 DNA from monocytes. However, further studies with quantitative PCR and virus isolation followed by DNA amplification and sequencing are necessary. In the present study, this different pattern was observed in both treated and untreated patients, but whether this variant is naturally- or treatment-selected also needs further investigation.

RS, Tedder RS. Expression of HIV-1 in the cerebrospinal fluid detected by the polymerase chain reaction and its correlation with central nervous system disease. AIDS $1991 ; 5: 797-803$.

13. Yolken RH, Li S, Perman J, Viscidi R. Persistent diarrhea and fecal shedding of retroviral nucleic acids in children infected with human immunodeficiency virus. J Infect Dis 1991 ; 164: 61-66.

14. Mermin JH, Holodniy M, Katzenstein DA, Merigan TC. Detection of human immunodeficiency virus DNA and RNA in semen by the polymerase chain reaction. $J$ Infect Dis 1991 ; 164: 769-772.

15. Pang S, Vinters HV, Akashi T, O'Brien WA, Chen ISY. HIV-1 env sequence variation in brain tissue of patients with AIDS-related neurologic disease. $J$ Acquired Immune Defic Syndr 1991; 4: 1082-1092.

16. Varma V, Rimland D, Srinvasan A, Swan D. Diagnosis of HIV infection employing polymerase chain reaction (PCR) on paraffin embedded tissue. Lab Invest 1989; 60: 101A.

17. Sheppard HW, Ascher MS, Busch MP et al. A multicenter proficiency trial of gene amplification (PCR) for the detection of HIV-1. J AIDS 1991; 4: 277-283.

18. Pantaleo G, Graziosi C, Fauci AS. The immunopathogenesis of human immunodeficiency virus infection. $N$ Engl $J \mathrm{Med}$ 1993; 328: 327-335.

19. Klatzman D, Champagne E, Chamaret S et al. T-lymphocyte T4 molecule behaves as receptor for human retrovirus LAV. Nature $1984 ;$ 312: 767-771.

20. Busch MP, Eble BE, Khayam-Bashi $\mathrm{H}$ et al. Evaluation of screened blood donations for human immunodeficiency virus type 1 infection by culture and DNA amplification of pooled cells. $N$ Engl J Med $1991 ; 325$ : $1-5$.

21. Quirós E, García F, González I, Cabezas T, Bernal MC, Maroto MC. Diagnosis of HIV-1 infection by PCR with two primer pairs. Eur J Epidemiol 1993; 9: 426-429.

22. Wages JM, Hamdallah M, Calabro MA et al. Clinical performance of a polymerase chain reaction testing algorithm for diagnosis of HIV-1 infection in peripheral blood mononuclear cells. J Med Virol 1991; 33: 58-63.

23. McElrath MJ, Pruett JE, Cohn ZA. Mononuclear phagocytes of blood and bone marrow: comparative roles as viral reservoirs in human immunodeficiency type 1 infections. Proc Natl Acad Sci USA 1989; 86: 675-679. 